\title{
The Environmental Cofactors in Carcinogenesis in High Risk HPV/HIV-Positive Women
}

\author{
Michele Paulo, Alex Bittencourt Borges, Geraldo Duarte, Silvana Maria Quintana, \\ Marlise Bonetti Agostinho Montes and Maria Regina Torqueti Toloi \\ Department of Clinical, Toxicological and Bromatological Analysis, Faculty of Pharmaceutical Sciences of Ribeirão Preto, \\ University of São Paulo; São Paulo, SP, Brazil
}

\begin{abstract}
The objective of the present study was to assess the presence of human papilloma virus (HPV) in HIV-infected women, with comparison between the Papanicolaou cytologic technique and the molecular PCR technique, as well as to determine the type of HPV, to measure cellular immunocompetence and to identify the presence of risk factors for the acquisition of HPV infection. Thirty HIV-infected women were selected. Vaginal and endocervical samples were collected from 27 of them. The smears were examined by 3 experienced cytologists to diagnose the presence of HPV by the Papanicolaou technique and the results were compared to HPV detection and typing by PCR. HPVinfected patients were interviewed in order to identify the presence of risk factors for the acquisition of the virus. Eight of the 27 patients analyzed (29\%) presented HPV in endocervical samples submitted to PCR, 6 of them (75\%) presented HPV involving a high risk of development of cervical cancer. For 5 of these patients, the cytologic diagnosis was not confirmed by PCR. When cellular immunocompetence was related to HPV infection, PCR revealed a diagnosis of $\mathrm{HPV}$ in $\mathbf{3 7 . 5 0 \%}$ of the patients at intermediate risk for $\mathrm{HPV}$ infection and in $83.33 \%$ of the patients at high risk for HPV infection. These immunologically compromised HPV-infected patients are at higher risk of developing cervical neoplasia. We showed here that PCR is adequate for HPV detection and that, if only the Papanicolaou method is used for the follow-up of these patients, we will not provide good prevention of cervical cancer.
\end{abstract}

Key-Words: HPV, HIV-infected women, cervical cancer, carcinogenesis, antiretroviral therapy.

Human papillomaviruses (HPV) are epitheliotropic and have a high affinity for the genital tract. Infection with some HPV genotypes is considered to be of high risk for the development of cervical cancer. Persistent infection with oncogenic HPV is a necessary, but not sufficient, condition for the development of cervical cancer. The joint action of other environmental cofactors with HPV is necessary to influence the transition from cervical HPV infection to cervical cancer. Among such cofactors are HIV, smoking and sexual activity [1].

Invasive cervical carcinoma in adolescents and adults, when associated with HIV-positive serology, defines the diagnosis of AIDS, indicating impaired cell immunity [2,3]. When associated with HIV infection, cervical carcinomas have proved to be more aggressive and refractory to traditional treatment, with high recurrence rates (39\% in seropositive patients versus $9 \%$ in patients with negative serology) and with severity directly related to the degree of immunosuppression. They also present an uncommon pattern of metastasis and are related to a poorer prognosis than those not associated with HIV [4,5].

The study of HPV infection among HIV-infected women has attracted the attention of investigators because of the prevalence about 5 times higher of this infection among them

Received on 17 September 2006; revised 12 February 2007.

Address for correspondence: Dr. Maria Regina Torqueti Toloi. Faculty of Pharmaceutical Sciences of Ribeirão Preto. University of São Paulo, Brazil. Department of Clinical, Toxicological and Bromatological Analysis. Avenida do Café S/N, Bloco: M, Sala: 327, Bairro: Monte Alegre, Zip code: 14040-903. E-mail: torqueti@fcfrp.usp.br.

The Brazilian Journal of Infectious Diseases 2007;11(2):189-195. (C) 2007 by The Brazilian Journal of Infectious Diseases and Contexto Publishing. All rights reserved. compared to non-HIV-infected women with a high risk behavior. This interest is focused on the high potential of HPV infection to associate with cervical neoplasias and their precursor lesions among HIV-infected women, at different frequencies [5,6]. HIV infection probably acts as one of these factors, activating cell transformation by still poorly understood mechanisms or by depressing local immunity in the genital tract [1].

Peripheral blood $\mathrm{CD}_{4}+$ lymphocyte counts have prognostic implications in the evolution of HIV infection since they represent a measure of cellular immunocompetence. In the United States, the Centers for Disease Control and Prevention emphasizes the importance of $\mathrm{CD}_{4}+$ lymphocyte counts in the characterization of the clinical conditions related to HIV, with counts of less than 200 cells/mL blood or a percentage of less than $14 \%$ of total lymphocytes being considered critical. In Brazil, the Ministry of Health has established that lymphocyte counts of 50 to 200 cells $/ \mathrm{mm}^{3}$ characterize a stage with a high probability of the onset of opportunistic diseases [3].

Considered as a whole, data reported by Palefski et al. [6] suggest that measurements of immunity $\left(\mathrm{CD}_{4}+\right.$ lymphocyte counts and HIV viral load) together with HPV typing, particularly when HPV is detected persistently, could be valuable for the identification of HIV-infected women at high risk of developing cervical neoplasia. They should be followed up by frequent cytologic examinations and submitted to more sensitive methods for the detection of HPV infection.

Therapeutic agents for the treatment of HIV infection are currently available on the market. The use of these medications has become known as highly active antiretroviral therapy (HAART). One of the main objectives of HAART is to reduce the viral load to undetectable levels (below 50 to 80 copies/ $\mathrm{mL}$ ) within a period of 6 months, delaying the progression of 
immunodeficiency and/or restoring immunity as much as possible, increasing the time and quality of life of the infected person. The efficiency of HAART can be evaluated on the basis of its capacity to reduce the viral load to satisfactory levels, i.e., below the detection limit, after 6 months. A 99\% reduction of the initial viral load after 12 to 16 weeks is considered to be a positive result of HAART [3].

The patients studied in the present investigation are at high risk of developing cervical cancer because of their important risk factor represented by AIDS. The objective of the present study was to determine the presence of HPV in these women, with a comparison of a cytologic technique (Papanicolaou) and a molecular technique (PCR), as well as to determine the type of HPV and to measure cellular immunocompetence and other associated risk factors such as smoking, sexual activity, type of delivery, and use of contraceptive methods.

\section{Materials and Methods}

Thirty HIV-infected women attended at the Service of Infectious-Contagious Diseases in Gynecology and Obstetrics (SEMIGO) and at the Special Unit of Infectious Diseases (UETDI), both belonging to the University Hospital, Faculty of Medicine of Ribeirão Preto (HC-FMRUSP), were selected. The patients were submitted to gynecologic examination, including the collection of vaginal and endocervical samples (Papanicolaou) and an endocervical smear for the analysis of HPV DNA [9].

For the diagnosis based on the Papanicolaou method, 3 cytologists examined the smears and the results obtained were compared to the detection and typing of HPV by PCR according to the protocol of Gravitt et al. [9].

As an internal control of PCR, a 268 bp fragment of the bglobin gene was amplified using the GH20/PC04 primers in order to assure DNA integrity. As a negative control, the samples were replaced with water [10,11]. One of the initial samples, denominated 6T0, was tested in the Laboratory of Virology of the Ludwig Institute for Cancer Research. The positive control used was the DNA of a human cell line (HeLa) with the HPV genome integrated serotype 18. This sample was used as the control of amplification of both the fragment relative to HPV and the fragment relative to the b-globin gene. The samples were submitted to $2 \%$ agarose gel electrophoresis for 50 minutes, with constant $100 \mathrm{~mA}$ amperage, followed by staining with $1 \%$ ethidium bromide. The samples were compared to the positive control cited above and those showing amplification of the $450 \mathrm{bp}$ segment of HPV and of the 268 bp segment of b-globin were considered to be positive. The samples for PCR were typed by restriction fragment length polymorphism (RFLP) produced by the restriction enzymes Bam H I, Hae III, Hin f I, Pst I, RSA I (Amersham Pharmacia Biotech, Little Chalfont - Burckinghamshire, UK) and Dde (Roche, F.Hoffmann - La Roche LTD Corporate Communications Grenzacherstrasse - Switzerland), according to the method of Bernard et al. [12]. The products of enzymatic digestion were separated by $10 \%$ acrylamide gel electrophoresis for 90 minutes at constant $100 \mathrm{~mA}$ amperage. After ethidium bromide staining and visualization under UV light, the patterns were compared to the DNA molecular weight standard, FX174 RF DNA/Hae III Fragments (Invitrogenä Life Technologies, Carlsbad, California). The viral types were compared to the standard described by Bernard et al. [12]

Epidemiological and socioeconomic data were obtained by a standard interview using a structured questionnaire. The patients were asked about their sexual behavior (number of partners along life, and number of partners during the last year and during the last 6 months), the type of contraceptive method used, the type of delivery, smoking habit, and the consumption of alcoholic beverages. Patients younger than 18 years and virgin patients were excluded from the study, which was approved by the Ethics Committee on Research of the Clinical Hospital of the School of Medicine of Ribeirão Preto, University of São Paulo. All subjects were volunteers and gave written informed consent.

\section{Results}

PCR and Viral Typing

Thirty HIV-infected patients were selected for the present study. Three of them did not attend the medical visits and were excluded from the study. Twenty-seven women were submitted to gynecologic examination and to collection of an endocervical smear. The material was submitted to cytological exams (triple cytology or Papanicolaou test) and to PCR for the diagnosis of HPV.

Among the samples tested by PCR, 8 were positive for HPV DNA (patients 1, 2, 3, 6, 9, 10, 15, and 16). Amplification of fragments of approximately $450 \mathrm{bp}$, characteristic of HPV, occurred in $29.6 \%$ of the cases (8/27), as shown in Figure 1.

For cytological examination, each sample was tested by 3 different cytologists who were unaware of the serologic status of the patients regarding HIV. The first examiner detected a picture suggestive of HPV in 8 patients (numbers 2, 10, 11, 13, 15, 18, 23 and 24), the second detected it in 4 patients (numbers 2, 11, 13 and 23) and the third detected it in only 1 patient (number 13). These results are presented in Table 1.

Of the 8 patients found to be positive for HPV DNA by PCR (Figure 1), only patient number 10 received a diagnosis of class III, suggesting moderate dysplasia. Patient number 13 showed moderate dysplasia according to the Papanicolaou classification, but did not show the presence of HPV by PCR (Table 1).

According to the RFLP technique, the viral types detected in the 8 positive samples for HPV DNA (Figure 1) were 16, 26, 56, 59 and 69. HPV type 69 was detected in patients 1 and 9, HPV type 56 was detected in patients 2 and 16, HPV type 16 was detected in patient 10 , and HPV type 59 was detected in patient 6 . All of these types are considered to be of high risk for the development of cervical carcinoma [13]. These results are presented in Table 2. HPV type 26 was detected in patients 3 and 15; this type is considered to be of low risk for the 
development of cervical carcinoma, being more associated with benign lesions such as common genital warts [14].

\section{Epidemiologic Characteristics}

The epidemiological data of the patients are presented in Table 3. Patient age ranged from 18 to 52 years, mean age was 33 years and the most frequent age range was 18 to 39 years (66\%-18/27). Married and cohabiting women corresponded to $51.8 \%(14 / 27)$ of the participants in the study.

Mean age at first sexual relation, with vaginal penetration, was 17 years (range: 12-33). A considerable proportion of these women $(88 \%, 24 / 27)$ had their first sexual experience between 12 and 22 years. Six participants (22.2\%, 6/27), who had been or still were sex professionals, were unable to establish the number of sex partners with whom they had had contact. For 17 participants, the mean number of sex partners was 3 along life. The mean number of partners during the last 6 months of the last year was less than one (0.9), since 4 participants did not have sexual relations during the study period and 1 of them reported that she still was a sex professional.

Thirteen participants (13/27-48\%) were taking or had been taking oral contraceptives (OC) for a mean time of 48 months (range: 7 months to 10 years). Regular use of a preservative by their partners was reported by 10 patients (48\%-13/27), and the concomitant use of a preservative and an OC was reported by 3 of them. Two participants had submitted to tube ligation as a contraceptive method.

Eight women (29.6\%-8/27) reported having had a sexually transmissible disease (STD) and 8 (29.6\%-8/27) reported that their partner had suffered a STD.

Sixteen patients (59.2\%-16/27) declared that they were or had been smokers, most of them (51.8\%-14/27) consuming 10 to 30 cigarettes a day. Smoking started, on average, at 15 years of age and was maintained for a mean time of 16 years (range: 5 to 31 years).

The mean number of pregnancies and of liveborn children was 3. Four patients had at least one abortion. Vaginal delivery was the predominant type, with $59.2 \%$ (16/27) of the participants having delivered at least 1 child by this route. Four patients were nulliparae.

\section{Highly Active Antiretroviral Therapy (HAART)}

Sixteen patients (numbers 1, 3, 8, 11, 12, 13, 15, 17, 19, 20, 21, 22, 23, 24, 25 and 26) did not receive HAART but had been followed up for a period of time ranging from 98 to 309 days. Eleven patients had received HAART during a period of follow-up ranging from 125 to 351 days. Normally, the patients had started therapy at intervals ranging from 7 to 351 days after the initial visit (numbers 2, 4, 5, 6, 7, 9, 10, 14, 16, 18, and 27) Five of these patients (numbers 2, 6, 9, 10 and 16) were found to have HPV DNA by the PCR technique.

As shown in Table 4, all patients receiving HAART presented increased $\mathrm{CD}_{4}+$ counts and decreased HIV viral loads. The Ministry of Health recommends that all patients in the early phase of treatment, as was the case for the present patients, receive potent or triple antiretroviral schemes [3]. As shown in Table 4, the initial HAART selected for the present patients was the combination of 2 nucleoside analogue reverse transcriptase inhibitors (NRTI), lamivudine (3TC) plus stavudine (d4T) or zidovudine (AZT), and a non-nucleoside analogue reverse transcriptase inhibitor (NNRTI), nevirapine or efavirenz. Two patients (numbers 6 and 14) received a combination of AZT and 3TC (NRTI) with nelfinavir.

\section{Discussion}

Virus Detection and Typing

HPV was detected by PCR in endocervical samples from 8 of the 27 patients studied, with 6 of them (75\%) presenting serotypes 16, 56, 59 and 69, of high risk for the development of cervical cancer. The HPV 16 genotype was detected in only 1 patient (number 10), the HPV 56 genotype was diagnosed in 2 patients (numbers 2 and 16), HPV 59 was detected only in patient no. 6, HPV 56 was diagnosed in 2 patients (numbers 2 and 16), and HPV 69 in patients nos. 1 and 9. Two other patients (numbers 13 and 15) presented HPV type 26, of low risk for the development of cervical cancer, corresponding to a percentage of $25 \%$.

Among the 27 samples analyzed by the 3 examining cytologists, examiner no. 1 detected cytologic changes suggestive of HPV in patients 2, 10, 11, 13, 15, 18, 23, and 24. In 5 of these patients (numbers 11, 13, 18, 23 and 24) the cytologic diagnosis was not confirmed by PCR. Cytologist no. 2 detected cytologic changes suggestive of HPV in 4 patients (numbers 2,11, 13 and 23). Only one of these results, for patient number 2, was confirmed by PCR. Cytologist number 3 detected cytologic changes suggestive of HPV only in patient 13 and this result was not confirmed by PCR. This was due to the fact that cytopathologic examination, which has been widely used and accepted as a screening method for the prevention of cancer of the cervix, has a low sensitivity of about $70 \%$ owing to the intra- and interobserver variability involved in the exam, which leads to a large number of falsenegative results [18-20]. In the present study, even though the patient sample was small, the cytopathologic examination showed only $38 \%$ sensitivity compared to PCR.

In 4 cases (patients 1, 6, 9 and 16), high risk HPV infection was detected by PCR, whereas none of the examining cytologists had detected cytologic changes suggestive of HPV infection (Tables 1 and 2).

Risk Cofactors for the Progression of HPV Infection to Cervical Cancer

\section{Sexually Transmissible Diseases}

STDs are considered to be important cofactors for the progression of HPV infection to more severe lesions [15]. All the women studied here, by being infected with HIV, were already under the influence of this cofactor. Eight patients (8/ 27-29.6\%) reported having been infected with some STD other than HIV infection and 8 (29.6\%) reported that their partners had been infected with an STD other than HIV infection (Table 
Figure 1. Product of the amplification of the viral genome of HPV generated after PCR.

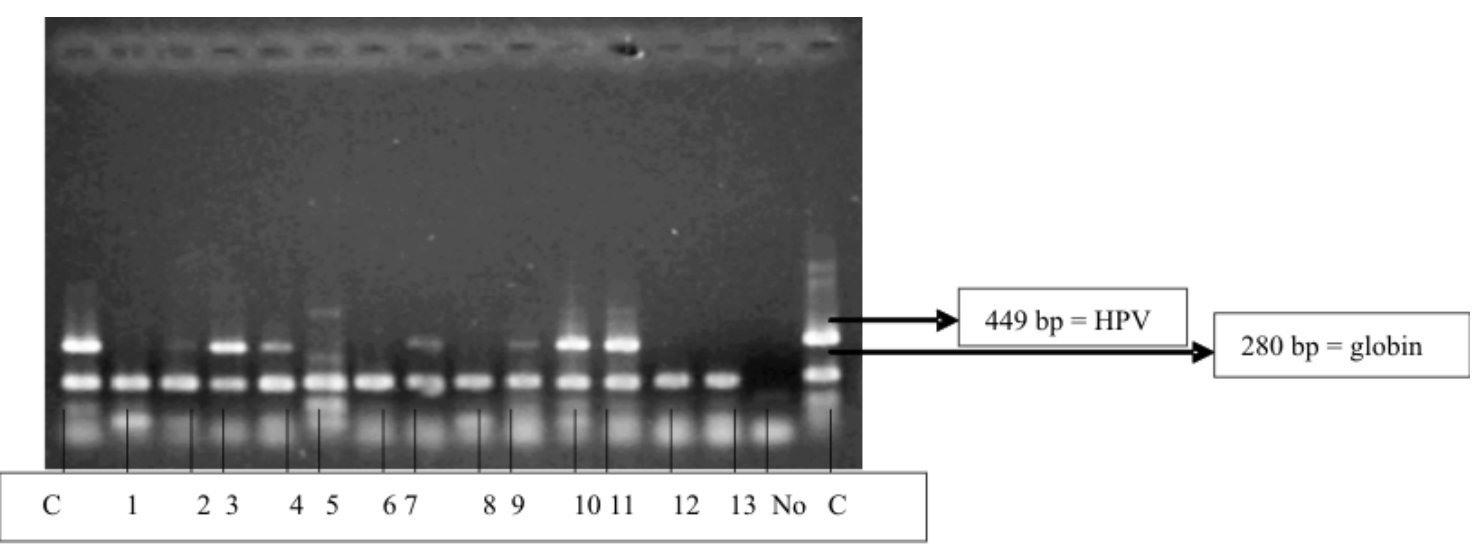

$\mathrm{C}=$ =positive control; the numbers from 1 to 13 refer to patients 1 to 13 ; No=negative control; 268 bp=amplification of the human $\beta$-globin gene used as internal control; $449 \mathrm{bp}=$ amplification of the HPV gene. All samples were tested in duplicate on different dates in a random manner.

Table 1. Comparison of the results obtained by the molecular (PCR) and cytologic (Papanicolaou) techniques

\begin{tabular}{|c|c|c|c|c|c|c|c|}
\hline \multirow[b]{2}{*}{ Patient } & \multicolumn{2}{|c|}{ C1 } & \multicolumn{2}{|c|}{ C2 } & \multicolumn{2}{|c|}{ C3 } & \multirow[b]{2}{*}{ PCR } \\
\hline & HPV & Class & HPV & Class & HPV & Class & \\
\hline 1 & & II & & & & I & positive \\
\hline 2 & positive & II & positive & & & II & positive \\
\hline 3 & & II & & II & & II & positive \\
\hline 4 & & II & & II & & II & \\
\hline 5 & & II & & II & & II & \\
\hline 6 & & II & & I & & I & positive \\
\hline 7 & & II & & II & & II & \\
\hline 8 & & II & & II & & II & \\
\hline 9 & & II & & II & & II & positive \\
\hline 10 & positive & III & & II & & II & positive \\
\hline 11 & positive & II & positive & II & & II & \\
\hline 12 & & II & & II & & II & \\
\hline 13 & positive & III & positive & II & positive & II & \\
\hline 14 & & II & & II & & II & \\
\hline 15 & positive & II & & II & & II & positive \\
\hline 16 & ** & & & & & & positive \\
\hline 17 & & II & & I & & I & \\
\hline 18 & positive & II & & II & & II & \\
\hline 19 & & I & & I & & I & \\
\hline 20 & & I & & I & & I & \\
\hline 21 & & II & & II & & II & \\
\hline 22 & & I & & I & & I & \\
\hline 23 & positive & II & positive & II & & II & \\
\hline 24 & positive & & & II & & II & \\
\hline 25 & & I & & II & & II & \\
\hline 26 & & II & & I & & II & \\
\hline 27 & & $* *$ & & & & & \\
\hline
\end{tabular}

$\mathrm{C} 1=$ examining cytologist 1 ; $\mathrm{C} 2=$ examining cytologist 2; C3=examining cytologist 3 . The patients whose results are blank presented other cytologic results not associated with the molecular or cytologic diagnosis of HPV. **The material obtained from patients 16 and 27 for cytologic examination was unsatisfactory for the above exams. 
Table 2. Types of human papillomavirus detected by the restriction fragment length polymorphism technique in the samples from HIV-infected patients and their respective risks for the development of cervical cancer

\begin{tabular}{ccc}
\hline Patient & HPVType & Risk \\
\hline 1 & 69 & high \\
2 & 56 & high \\
3 & 26 & low \\
6 & 59 & high \\
9 & 69 & high \\
10 & 16 & high \\
15 & 26 & low \\
16 & 56 & High \\
\hline
\end{tabular}

Table 3. Epidemiologic and socioeconomic (socioeconomic behavioral and reproductive history)

\begin{tabular}{|c|c|c|}
\hline Characteristic & N/Total & $\%$ \\
\hline \multicolumn{3}{|l|}{ Age (years) } \\
\hline $18-25$ & $4 / 27$ & 14.8 \\
\hline $25-32$ & $10 / 27$ & 37.0 \\
\hline $32-39$ & $4 / 27$ & 14.8 \\
\hline 39-46 & $5 / 27$ & 18.5 \\
\hline$\geq 46$ & $4 / 27$ & 14.8 \\
\hline \multicolumn{3}{|l|}{ Marital status } \\
\hline Cohabiting & $10 / 27$ & 37.0 \\
\hline Married & $4 / 27$ & 14.8 \\
\hline Widow & $3 / 27$ & 11.1 \\
\hline Single & $6 / 27$ & 22.2 \\
\hline Separated/Divorced & $4 / 27$ & 14.8 \\
\hline \multicolumn{3}{|l|}{ Age at first sexual relation } \\
\hline $12-17$ & $14 / 27$ & 51.8 \\
\hline $17-22$ & $10 / 27$ & 37.0 \\
\hline $22-27$ & $2 / 27$ & 7.4 \\
\hline$\geq 32$ & $1 / 27$ & 3.7 \\
\hline \multicolumn{3}{|l|}{ Number of partners/life } \\
\hline $1-3$ & $13 / 27$ & 48.1 \\
\hline $3-5$ & $3 / 27$ & 11.1 \\
\hline $5-7$ & $2 / 27$ & 7.4 \\
\hline $7-8$ & $3 / 27$ & 11.1 \\
\hline Undefined & $6 / 27$ & 22.2 \\
\hline \multicolumn{3}{|c|}{ Sexually transmissible diseases (STD) } \\
\hline \multicolumn{3}{|l|}{ Patients } \\
\hline No/Unknown & $16 / 27$ & 59.2 \\
\hline Lesions associated with HPV & $3 / 27$ & 11.1 \\
\hline Syphilis/herpes & $3 / 27$ & 11.1 \\
\hline Unspecified STD & $5 / 27$ & 18.5 \\
\hline \multicolumn{3}{|l|}{ Partners } \\
\hline No/Unknown & $19 / 27$ & 70.3 \\
\hline Lesions associated with HPV & $4 / 27$ & 14.8 \\
\hline Unspecified STD & $4 / 27$ & 14.8 \\
\hline
\end{tabular}

Table 3. (Continued)

\begin{tabular}{lcr}
\hline $\mathrm{N}$ of cigarettes/day & \multicolumn{1}{c}{0} \\
& $11 / 27$ & 40.7 \\
$<10$ & $3 / 27$ & 11.1 \\
$10-20$ & $7 / 27$ & 25.9 \\
$20-30$ & $4 / 27$ & 14.8 \\
$\geq 40$ & $2 / 27$ & 7.4 \\
Type of delivery* & & \\
Cesarean section & $5 / 23$ & 21.7 \\
Normal & $8 / 23$ & 34.7 \\
Normal and cesarean section & $8 / 23$ & 34.7 \\
Forceps & $1 / 23$ & 4.3 \\
$\quad$ Normal and forceps & $1 / 23$ & 4.3 \\
\hline *Four nulliparous patients. & &
\end{tabular}

3). However, this information is of relative value since it was obtained by interviews with the patients. This type of information is influenced by multiple factors such as the inability to understand the technical terms used in previous diagnoses, embarrassment during the interview, forgetfulness, confusion, and difficulty in dialogue and in the patient's relationship with their partners, among many others.

\section{Vaginal Deliveries}

The risk of HPV infection progressing to cancer of the uterine cervix among women younger than 45 years is directly proportional to the number of pregnancies resolved by vaginal delivery, probably due to hormonal events related to the second and third trimesters of pregnancy, such as ectopy and metaplasia in the transformation zone [16].

Due to the number and type of deliveries and to age, 3 patients (numbers 14, 15 and 22) had been exposed to this risk cofactor for neoplastic progression.

\section{Smoking}

Studies published by IARC have shown that the risk of developing cancer of the cervix for HPV-infected women is about twice higher among women with a history of smoking 20 cigarettes a day for at least 6 years [14]. Four participants in the present study (numbers 6, 15, 22 and 25) fulfilled these criteria, with infection with oncogenic HPV and a smoking history ranging from 7 to 21 years. Thus, these women were exposed to a highly relevant cofactor capable of influencing in a significant manner the progression of cervical infections to high grade lesions and invasive cervical cancer.

T-CD + Lymphocyte Count and Quantitation of Viral Load

The elevated prevalence of high risk HPV among HIVinfected women is believed to be related more to immunosuppression, which leads to the persistence and reactivation of latent infections that culminate in the recent acquisition of new HPV types. The immunity determination and HPV typing are important parameters for the identification 
Table 4. Type of antiretroviral therapy, HPV infection, T-CD + lymphocyte count and quantification of HIV viral load in the HIVinfected patients studied

\begin{tabular}{|c|c|c|c|c|c|c|c|c|}
\hline \multicolumn{3}{|c|}{ Antiretroviral therapy } & \multirow{2}{*}{$\begin{array}{c}\text { Case } \\
\mathbf{N}^{\mathbf{0}}\end{array}$} & \multirow{2}{*}{$\begin{array}{l}\text { HPV } \\
\text { DNA }\end{array}$} & \multicolumn{2}{|c|}{ T-CD + lymphocytes } & \multicolumn{2}{|c|}{ HIV viral load } \\
\hline NRTI & NNRTI & PI & & & T0 & T1 & T0 & T1 \\
\hline D4T+3TC & Efavirenz & & 9 & 69 & 15 & 68 & 87.000 & BDL \\
\hline \multirow[t]{2}{*}{$\mathrm{AZT}+3 \mathrm{TC}$} & & Nelfinavir & 6 & 59 & 341 & 587 & 130.000 & BDL \\
\hline & & & 14 & _- & 283 & 402 & 20.000 & 4.623 \\
\hline \multirow[t]{2}{*}{$\mathrm{AZT}+3 \mathrm{TC}$} & Nevirapine & & 4 & - & 331 & 675 & 12.000 & 678 \\
\hline & & & 27 & . & 357 & \#\# & \#\# & \#\# \\
\hline \multirow{6}{*}{$\mathrm{AZT}+3 \mathrm{TC}$} & Efavirenz & & 7 & & 88 & 472 & \#\# & BDL \\
\hline & & & 2 & 56 & 20 & 102 & \#\# & BDL \\
\hline & & & 16 & 56 & 76 & 136 & 300.000 & BDL \\
\hline & & & 18 & - & 12 & 162 & 132.080 & BDL \\
\hline & & & 5 & 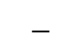 & \#\# & 241 & \#\# & 10.042 \\
\hline & & & 10 & 16 & 62 & 87 & 299.036 & 130 \\
\hline
\end{tabular}

NRTI=nucleoside reverse transcriptase inhibitor; NNRTI=non-nucleoside reverse transcriptase inhibitor; PI=protease inhibitor, AZT=zidovudine; $3 \mathrm{TC}=$ lamivudine; $\mathrm{d} 4 \mathrm{~T}=$ =stavudine; $\mathrm{T} 0=$ =initial collection; $\mathrm{T} 1=$ final collection, $\mathrm{BDL}=$ below the detection limit; \#\#=not available; -=negative HPV DNA; T-CD + lymphocytes=(cells $\left./ \mathrm{mm}^{3}\right)$; HIV viral load= $(\mathrm{copies} / \mathrm{mL})$.

Table 5. Patient classification regarding the risk of HPV infection according to their respective viral load (HIV) and $\mathrm{CD}_{4}+$ count obtained from their medical records

\begin{tabular}{lccll}
\hline Risk & $\mathbf{C D}_{\mathbf{4}}+\mathbf{c o u n t}\left(\mathbf{c e l l} \mathbf{s} / \mathbf{m m}^{\mathbf{3}}\right)$ & HIV viral load (copies/mL) & Patients & Patient with HPV \\
\hline Low & $>200$ & $<20.000$ & $4,5,7,11,12,13,14,17$ and 24 & $* * *$ \\
Intermediate & $>200$ & $<20.000$ & $3,6,8,15,19,20,22,23$ & $3,6,1$ and 5 \\
High & $<200$ & & $1,2,9,10,16$ and 21 & $1,2,9,10$ and 16 \\
\hline
\end{tabular}

*** Absence of HPV determined by PCR. Patients 18, 25 and 27 are not mentioned in the table because their medical records were not available.

of HIV-infected women at high risk to develop cervical neoplasia [5].

The combination of $\mathrm{CD}_{4}+$ lymphocyte count and HIV viral load has an excellent predictive value of the risk of HPV infection among HIV-infected women. According to Palefski et al. [5], at their lowest values $\left(\mathrm{CD}_{4}+\right.$ count of less than 200 cells $/ \mathrm{mm}^{3}$ and an HIV viral load higher than 20,000 copies/ $\mathrm{mL}$ ), both parameters are important for the activation and replication of HPV, as well as for its detection. HIV-infected women are at low risk when their $\mathrm{CD}_{4}+$ counts are higher than 200 cells $/ \mathrm{mm}^{3}$ and their viral loads lower than 20,000 copies/ $\mathrm{mL}$. Women whose $\mathrm{CD}_{4}+$ counts are higher than 200 cells/ $\mathrm{mm}^{3}$ and whose viral loads are higher than 20,000 copies/mL are at intermediate risk, and women with $\mathrm{CD}_{4}+$ lower than 200 cells $/ \mathrm{mm}^{3}$ regardless of viral load are at higher risk.

\section{Measurement of Immunity}

According to Table 4, which relates cell counts, HIV viral load and risk for HPV infection, none of the 9 patients considered to be at low risk for HPV infection presented a positive result for the diagnosis of HPV by PCR. Of the 8 patients considered to be at intermediate risk for HPV infection, 3 (numbers 3, 6 and 15) were found to be HPV positive by PCR, corresponding to $37.50 \%(3 / 8)$. Of the 6 patients considered to be at high risk for HPV infection, 5 (83.33\%) (numbers 1, 2, 9 and 16) were found to be HPV positive by PCR.
Cytology

Walboomers et al. (1992) concluded that cytopathologic examination is of low sensitivity (about 70\%), possibly leading to false-negative results. In the present study, we observed a lower percentage of agreement (38\%) when we compared the 2 techniques; however, we should point out the importance of the sample size when different studies are compared. The morphologic criterion for the diagnosis of HPV infection shows low sensitivity and specificity since it is based on morphologic criteria such as the presence of hypertrophic, bi- or multi-nucleated, hyperchromatic, koilocytotic, amphophilic or dysplasic cervical cells, whose detection depends largely on the good preparation and staining of the slides and on the experience of the examiner [17]. Thus, HIV-infected patients require a more specific technique for the detection of HPV infection, rather than simply a cytologic diagnosis.

The present results show that PCR detected 8 out of 27 patients with the presence of HPV DNA, with 6 of them being infected with HPV types involving a high risk of development of cervical cancer. The cytologic technique indicated changes suggestive of HPV in only 4 of these 8 women, showing low sensitivity.

The patients who participated in the present study, by being infected with HIV and immunocompromised and by being exposed to factors such as smoking, sexual activity and 
other STD, are at higher risk to develop cervical neoplasia and therefore require more sensitive techniques for the diagnosis of HPV. In the present study we showed that PCR is an adequate technique for this purpose and we also determined that the use of only the Papanicolaou test to monitor these patients will not provide good prevention of cervical cancer.

\section{References}

1. Cavalcanti S.M.B., Passos J.V.M., Zardo L.G., Oliveira L.H.S. Epidemiological aspects of human papillomavírus infection and cervical cancer in Brazil. J Infect 2000,40:80-7.

2. Teeter T. HIV causes AIDS. Bull Exp Treat AIDS. San Francisco AIDS Foundation, 2000.

3. Ministério da Saúde (MS). Manuais, Documentos e Recomendações as Técnicas Unidade de Assistência. AIDS: Etiologia, Clínica Diagnósticos e Tratamento. Available at http://www.aids.gov.br/ assistencia/etiologia_diagnostico.htm. Accessed April 3, 2001.

4. Berry J.M., Palefsky J.M. Anogenital Neoplasia. HIV Insite Knowledge Base Chapter. University of Califórnia, San Francisco. Published in November, 1998. Available at: http:// HIVinsite.ucsf.edu/InSite.jsp?doc=kb-06-04-02\&page=kb-06. Accessed August 1, 2001.

5. Lee Y.-C., Holcomb K., Buhl A., et al. Rapid progression of primary vaginal squamous cell carcinoma in a young HIV-1-infected woman. Gynecol Oncol 2000;78:380-2.

6. Palefsky J.M., Minkoff H., Kalish L.A., et al. Cervicovaginal human papillomavirus infection in human immunodeficiency virus-1 (HIV-1-positive and high-risk HIV-1-negative women). J Natl Cancer Inst 1999;91:226-36.

7. Howley P.M. Papillomavirinae: the viruses and their replication. In: FundamentalVirology. Fields B.N., Knipe D.M., Howley P.M., et al. (Eds). 3rd edn. Philadelphia: Linppincott-Raven Publishers; 1996, pp. 947-78.

8. Papanicolaou G.M., Trant H.F. The diagnostic value of vaginal smears in carcinoma of the uterus. Am J Obstet Gynecol 1941;42:193-206.

9. Gravitt P.E., Peyton C.L., Alessi T.Q., et al. Improved amplification of genital human papillomaviruses. J Clin Microbiol 2000;38:357-61.
10. Ting Y., Manos M.M. Detection and typing of genital human papillomaviruses. In: PCR protocols: A Guide to Methods and Applications. Innis M.A., Gelfand D.H., Sninsky J.J., White T.J. (Eds). San Diego: Academic Press; 1990. pp. 356-367.

11. Bauer H.M., Greer C.E., Manos M.M. Determination of genital human papillomavirus infection by consensus PCR amplification. In: Diagnostic Molecular Pathology: A Practical Approach. Herrington CS, McGee JO’D (editors). New York: Oxford University Press, 1992, vol 2, pp.131-52.

12. Bernard H.U., Chan S.Y., Manos M.M., et al. Identification and assessment of known and novel human papillomaviruses by polymerase chain reaction amplification, restriction length polymorphisms, nucleotide sequence, phylogenetic algorithms. J Infect Dis 1994;170:1077-85.

13. Munoz N., Bosch F.X., De Sanjose S., et al. Epidemiologic classification of human papillomavirus types associated with cervical cancer. New Engl J Med 2003;348:518-27.

14. Berry J.M., Palefsky J.M. Anogenital neoplasia. HIV-1 InSite Knowledge Base Chapter. University of California, San Francisco. Published November, 1998. Available at: http://HIV1insite.ucsf.edu/InSite.jsp?doc=kb-06-04-02\&page $=$ kb-06/. Accessed August 1, 2001.

15. Castellsagué X., Bosch F.X., Muñoz N.M. Environmental cofactors in HPV carcinogenesis. Vírus Res 2002;89:191-9.

16. Muñoz N., Franceschi S., Bossetti C., et al. Role of parity and human papillomavirus in cervical cancer: the IARC multicentric case-control study. Lancet 2002;359:1093-101.

17. Meisels A., Fortin R. Condylomatous lesions of the cervix and vagina. I. Cytologic patterns. Acta Cytol 1976;20:505-9.

18. Walboomers J.M.M., Melkert P.W.J., Van Den Brule A.J.C., et al. The polymerase chain reaction for human papillomavirus screening in diagnostic cytopathology of the cervix. In: Diagnostic Molecular Pathology: A Practical Approach. Herrington C.S., McGee J.O.’D. (Eds). New York: Oxford University Press, 1992, vol. 2, pp.153-72.

19. Walboomers J.M.M., de Roda Husman A.M., Snijders P.J.F., et al. Human papillomavirus in false negative archival cervical smears: implications for screening for cervical cancer. J Clin Pathol 1995; 48:728-32.

20. Milde-Langosch K., Riethodorf S., Löning T. Association of human papillomavirus infection with carcinoma of the cervix uteri and its precursor lesions: theoretical and practical implications. Virchows Arch 2000;437:227-33. 